\title{
CONCENTRATIONS AND HAZARDS OF POLYCYCLIC AROMATIC HYDROCARBONS IN HAWKED BAKED READY-TO-EAT FOODS IN NIGERIA
}

\author{
Chukwujindu M.A. Iwegbue* \\ Department of Chemistry, Delta State University P.M.B. 1 Abraka. Nigeria
}

(Received: 14 June 2014; accepted: 6 November 2014)

\begin{abstract}
The total concentrations of the $\Sigma 16$ polycyclic aromatic hydrocarbons (PAHs) were examined in some samples of baked ready-to-eat foods (cake, sausage roll, meat pie, burger, and bread) with a view to provide information on the hazards associated with the consumption of these hawked street foods. The measurements were performed by using a gas chromatograph-mass spectrometer (GC-MS) after hexane/dichloromethane extraction and clean-up. The total concentrations of the PAHs in these samples of ready-to-eat baked foods ranged from 427.4 to $1224 \mu \mathrm{g} \mathrm{kg}^{-1}, 289.9$ to $853.7 \mu \mathrm{g} \mathrm{kg}^{-1}, 574.4$ to $2333 \mu \mathrm{g} \mathrm{kg}^{-1}, 364.6$ to $2906 \mu \mathrm{g} \mathrm{kg}^{-1}$, and 15.7 to $213.1 \mu \mathrm{g} \mathrm{kg}^{-1}$ for cake, sausage roll, meat pie, burger, and bread, respectively. The results indicated that these baked ready-to-eat foods were mainly contaminated with 2-, 3-, and 4-ring PAHs. The concentrations of benzo(a)pyrene were less than $0.1 \mu \mathrm{g} \mathrm{kg}^{-1}$ in nineteen out of the twenty samples examined.
\end{abstract}

Keywords: ready-to-eat foods, polycyclic aromatic hydrocarbons, baked products, Nigeria

Polycyclic aromatic hydrocarbons (PAHs) are a group of over 100 compounds that consist of two or more fused rings in linear, angular, or cluster formation. PAHs often occur in the environment as a complex mixture of varying amounts and compositions. Of these, the United States Environmental Protection Agency has listed 16 PAHs as priority pollutants on the basis of the occurrence and carcinogenicity. Polycyclic aromatic hydrocarbons are products of pyrolytic processes, such as incomplete combustion of organic matter, and have received significant attention over the years because of their carcinogenic, genotoxic, and mutagenic properties (AKPAMBANG et al., 2009). Polycyclic aromatic hydrocarbons are widespread in food stuffs as a result of environmental pollution and some thermal treatments, which are used during the manufacturing of foods. Processing procedures such as smoking, roasting, drying, baking, or frying are recognized as the major sources of food contamination by PAHs (Ciecierska \& OBIEDZINSKi, 2007).

In Nigeria as in many other countries ready-to-eat foods, such as bread, cake, burger, sausage roll, and meat pie, etc., make up significant proportion of the daily food intake. At present, there are little or no data currently available on the polycyclic aromatic hydrocarbon profiles of these food items. The objective of this study was to determine the concentrations of USEPA 16 priority polycyclic aromatic hydrocarbons in these baked foods with a view of providing information on the hazards associated with the consumption of these hawked street foods.

\footnotetext{
* To whom correspondence should be addressed. Phone: +234-80-33864109, e-mail: maxipriestley@yahoo.com
} 


\section{Materials and methods}

\subsection{Reagents}

All chemicals and reagents used were of analytical grade. Dichloromethane (LC grade), alumina and silica gels were obtained from BDH (Poole, UK), while n-hexane was obtained from Aldrich (USA). A PAH standard mixture (NIST, Baltimore, MD) containing the 16 priority PAHs was used in this study and partial sodium salt-graft-poly(ethylene oxide) was from Sigma-Aldrich, Munich, Germany.

\subsection{Sample collection}

A total of 20 samples consisting of cake, meat pie, sausage roll, burger, and bread were purchased from roadside food vendors and hawkers in Abraka, Agbor, and Warri, Delta State, Nigeria. Within a particular type 3 to 4 samples were collected at different days of the week and minced together with a wooden rasp from which sub-samples were obtained for the determination of PAHs. The choice of the samples was carefully made to reflect popular types. The samples were stored at $4{ }^{\circ} \mathrm{C}$ prior to analysis.

\subsection{Sample extraction and clean-up}

Five grams of the sub samples were mixed with the same amount of drying material poly(acrylic acid), partial sodium salt-graft-poly(ethylene oxide) to make it free flowing. The resulting material was poured into $33 \mathrm{ml}$ cell and extracted with hexane and dichloromethane in an accelerated solvent extractor (ASE 200, Dionex Sunnyvale, CA). The extraction cells were filled with solvent, pressurised to $14 \mathrm{MPa}$, and heated to $120^{\circ} \mathrm{C}$ for $6 \mathrm{~min}$. The pressure and temperature were held constant for extra time of $5 \mathrm{~min}$ and the cell was rinsed with cold solvent ( $60 \%$ of cell volume) and purged with argon for $150 \mathrm{sec}$. The static extraction and purging steps were performed twice for each sample with fresh solvent and the extracts were combined (ZiEgenHALs et al., 2009).

The extracts were evaporated to $1 \mathrm{ml}$ and purified by solid phase extraction with $2 \mathrm{~g}$ of aluminium oxide ( $5 \%$ deactivated upper part) and $2 \mathrm{~g}$ of silica gel (5\% deactivated lower part). The PAHs were subsequently eluted with $15 \mathrm{ml}$ of hexane, $5 \mathrm{ml}$ of hexane and dichloromethane (9:1), and $20 \mathrm{ml}$ of hexane and dichloromethane (4:1). The eluted fractions were combined and evaporated to approximately $0.5 \mathrm{ml}$ by using rotary evaporator

\subsection{Chemical analysis}

PAHs were detected with gas chromatograph (HP 5890 series II Palo, Alto, CA) equipped with a HP5 capillary column (5\% diphenyl- $95 \%$ dimethyl polysiloxane) $(0.25 \mu \mathrm{m}$ film thickness, $0.25 \mathrm{~mm}$ i.d. $\times 30 \mathrm{~m}$ ) and interfaced with an HP5972 mass spectrometer. The carrier gas was helium $(99.999 \%)$ with a flow rate of linear velocity $1 \mathrm{ml} \mathrm{min}^{-1}$. The oven was programmed at $45^{\circ} \mathrm{C}$ for $2 \mathrm{~min}$, ramped at $10{ }^{\circ} \mathrm{C} \min ^{-1}$ to $290{ }^{\circ} \mathrm{C}$, and held for $8 \mathrm{~min}$. The mass spectrometer was operated in the electron ionization mode $\left(295^{\circ} \mathrm{C}\right.$ and $\left.70 \mathrm{eV}\right)$ using selected ion monitoring. The injector port and interface temperature were $290^{\circ} \mathrm{C}$ and $250^{\circ} \mathrm{C}$, respectively. One $\mu 1$ of each sample was injected in splitless mode. The target ions monitored for the analysis were $\mathrm{m} / \mathrm{z} 128,152,154,166,178,178,202,202,228,228,252,252,252$, 252, 278 and 278 while the confirmation ions were 127, 151, 153, 165, 176, 176, 101, 101, 114, 114, 126, 126, 126, 276, 276 and 278 for Nap, Acy, Ace, Flu, Phe, Ant, Flt, Pyr, BaA, 
Chy, BbF, Bkf, BaP, IndP, DahA, and BghiP, respectively. Quantification was carried out by external calibration method and all results were calculated at dry weight basis.

\subsection{Quality control/assurance}

In the absence of a certified reference material, the spike recovery method was adopted for validation of the analytical procedure. Some selected analysed samples were spiked with known concentrations of individual PAHs and reanalysing them. The spikes were applied to these samples at two concentration levels. The percent recoveries for the PAH compounds ranged from $71.5 \%$ to $96.5 \%$. The relative standard deviations for replicate analyses $(n=3)$ ranged between $1 \%$ and $9 \%$ for the PAH compounds. The detection and quantification limits (LODs and LOQs) were evaluated on the basis of noise obtained from the analysis of blank samples $(n=4)$. The LOD and LOQ were defined as the concentrations of the analyte that produced a signal-to-noise ratio of 3 and 10, respectively. The $\mathrm{r}^{2}$ values for the calibration curves in the concentration range of $2-100 \mu \mathrm{g} \mathrm{ml}^{-1}$ were in range of 0.9992 to 0.9998 , while LOD and LOQ values for the PAH compounds were in the range of 0.03 to $0.21 \mu \mathrm{g} \mathrm{kg}^{-1}$ and 0.1 to $0.7 \mu \mathrm{g} \mathrm{kg}^{-1}$, respectively. Analysis of variance and Tukey multiple-comparison tests were used to determine whether the concentrations of the PAHs varied significantly within and between the groups with $\mathrm{P}$ values less than $0.05(\mathrm{P}<0.05)$, which was considered to be statistically significant. The statistical calculations were performed with SPSS version 11.5.

\section{Results and discussion}

The total concentrations of PAHs in these products ranged from 427.4 to $1224 \mu \mathrm{g} \mathrm{kg}{ }^{-1}$, 289.9-854.7 $\mu \mathrm{g} \mathrm{kg}^{-1}, 574.4-2333 \mu \mathrm{g} \mathrm{kg}^{-1}, 364.6-2906 \mu \mathrm{g} \mathrm{kg}^{-1}$, and $15.7-213.1 \mu \mathrm{g} \mathrm{kg}^{-1}$ for cake, sausage roll, meat pie, burger, and bread, respectively (Table 1). The meat pie had higher concentrations of the $\Sigma 16$ PAHs compared to any other samples examined. The total PAH concentrations in the bread samples examined were similar to levels reported in the literature for breads (Ahmed et al., 2000; Nieva-CAno et al., 2001; ReY-Salgueiro et al., 2008; Orecchio \& Papuzza, 2009; Al-Rashdan et al., 2010). The PAH profiles of the individual samples varied significantly, which may be associated with the heating temperature and fuel types used in the baking process (AHMED et al., 2000).

Naphthalene was detected at concentrations of 2.2 to $255.1 \mu \mathrm{g} \mathrm{kg}^{-1}$, which constituted 6.6 to $69.3 \%$ of the $\Sigma 16$ PAHs. The cake samples had higher concentrations of Nap than the sausage roll, burger, meat pie, and bread samples. The 3 -ringed PAHs (Acy+Ace+Flu+Phe+Ant) were detected in $85 \%$ of the samples at concentrations in the range of 23 to $2277 \mu \mathrm{g} \mathrm{kg}^{-1}$, which constituted 9.5 to $97.6 \%$ of the $\Sigma 16$ PAHs. Anthracene was detected in $40 \%$ of these samples at concentrations between 29.1 and $1916 \mu \mathrm{g} \mathrm{kg}-1$, which constituted 3.4 to $82.1 \%$ of the $\Sigma 16$ PAHs. Higher anthracene concentrations were observed in the meat pie samples compared to the other ready-to-eat foods examined. Acenaphthylene and acenaphthene were detected in $80 \%$ and $75 \%$ at concentrations in the range of 0.8 to $410.9 \mu \mathrm{g} \mathrm{kg}^{-1}$ and 16 to $235.1 \mu \mathrm{g} \mathrm{kg}^{-1}$. The meat pie samples had higher concentrations of acenaphthylene and acenaphthene than the other products. In these samples, acenaphthylene and acenaphthene constituted 1.6 to $67.8 \%$ and 2.6 to $44.9 \%$ of the $\Sigma 16$ PAHs, respectively. Fluorene was detected in $55 \%$ of the samples at concentrations of 0.7 to $58.8 \mu \mathrm{g} \mathrm{kg}^{-1}$, while phenanthrene was detected in $15 \%$ of the samples at concentrations of 3.1 to $88.1 \mu \mathrm{g} \mathrm{kg}^{-1}$. Phenanthrene was not detected in the burger and bread samples examined. 


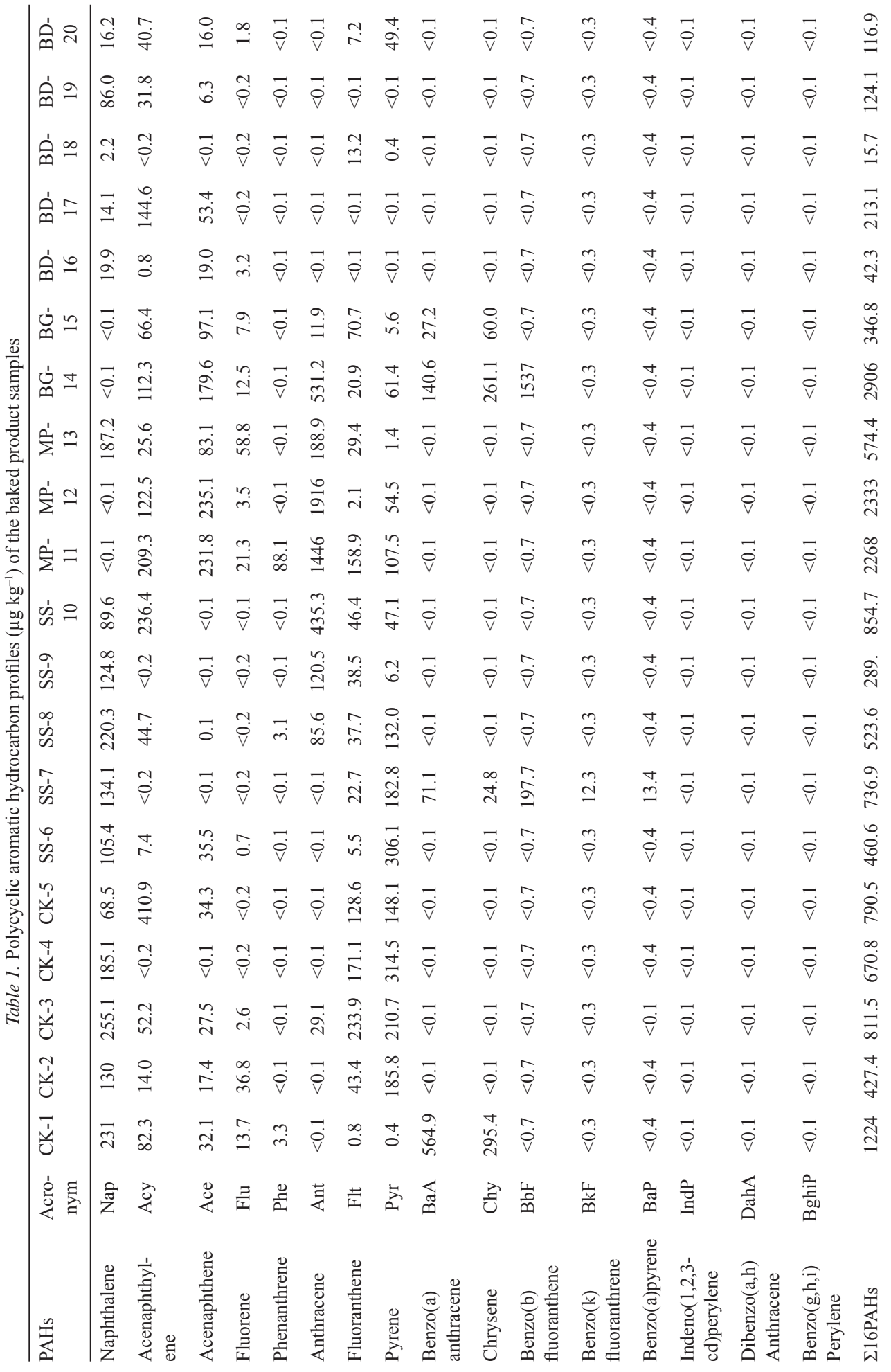




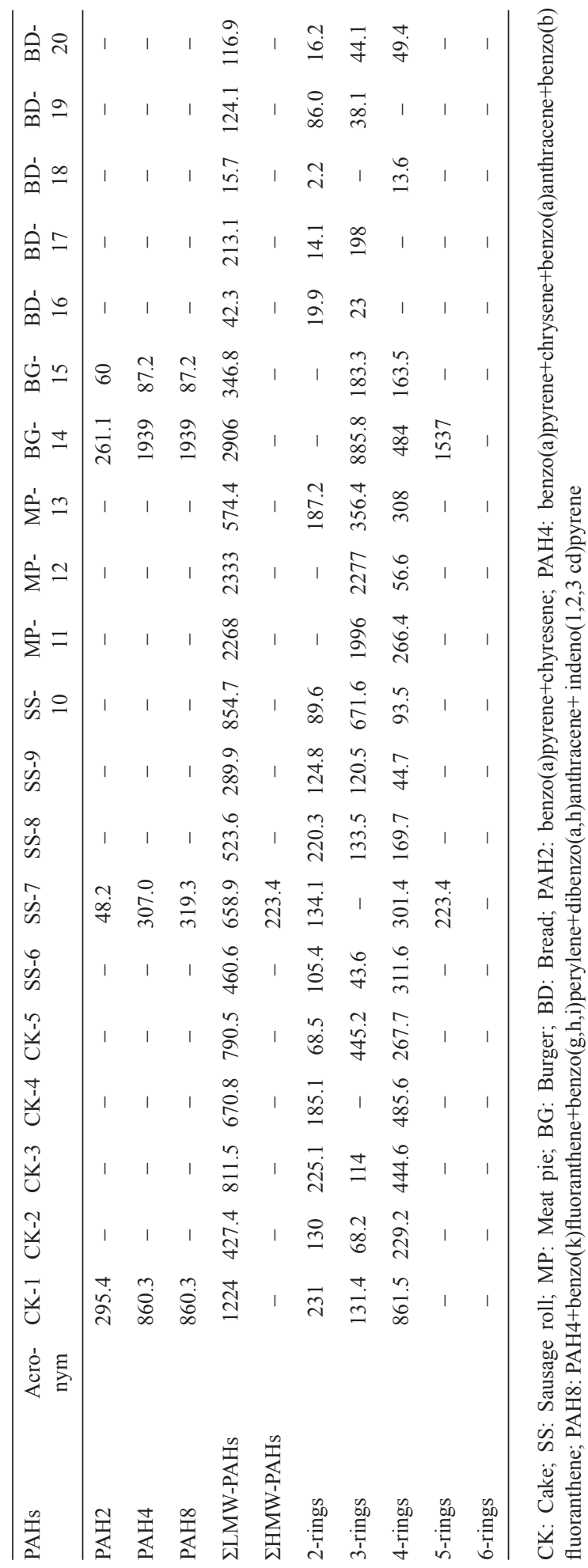


The 4-ringed PAHs (Flt $+\mathrm{Pyr}+\mathrm{BaA}+\mathrm{Chy})$ were detected in $85 \%$ of the samples investigated at concentrations of 13.6 to $861 \mu \mathrm{g} \mathrm{kg}^{-1}$. The 4-ringed PAH compounds constituted up to $86.6 \%$ of the $\Sigma 16$ PAHs in some of these samples. The highest concentrations of 4-ringed PAH compounds were observed in CK-1. Fluoranthene and pyrene were detected in $85 \%$ of the samples at concentrations of 0.8 to $233.9 \mu \mathrm{g} \mathrm{kg}-1$ and 0.4 to $314.5 \mu \mathrm{g} \mathrm{kg}^{-1}$, respectively. Pyrene was the dominant 4-ringed PAH compound in these samples in terms of concentrations. On average, the cake samples had higher concentrations of fluoranthene and pyrene than the other samples. Benzo(a)anthracene and chrysene were found only in samples CK-1, SS-7, BG-14, and BG-16. The sample CK-1 had higher concentrations of benzo(a) anthracene $\left(364.9 \mu \mathrm{g} \mathrm{kg}^{-1}\right)$ and chrysene $\left(295.4 \mu \mathrm{g} \mathrm{kg}^{-1}\right)$ than the other samples.

Five-ringed PAH compounds were detected in SS-7 and B-14 only. The 5-ringed PAHs constituted $30 \%$ and $52 \%$ of the $\Sigma 16$ PAHs in SS- 7 and B-14, respectively. Although, benzo(a) pyrene is considered as a suitable indicator for occurrence and effects of PAHs in food, but this relationship is not fully convincing, therefore, the European Food Safety Authority has suggested the use of PAH2: (chrysene+benzo(a)pyrene), PAH4:(PAH2+benzo(a) anthracene+benzo(b)fluoranthene), PAH8: (PAH4+benzo(k)fluoranthene+dibenz(a,h) anthracene+indeno(1,2,3-cd)perylen+benzo(g,h,i)perylene) as suitable indicators for the occurrence and effects of PAHs in food. The concentration of BaPin SS-7 (13.4 $\left.\mu \mathrm{g} \mathrm{kg}^{-1}\right)$ exceeded the prescribed limit of $1 \mu \mathrm{g} \mathrm{kg}^{-1} \mathrm{BaP}$ for cereal based products (EC, 2006). In Table 1, PAH8 concentrations of these products ranged from <LOQ to $1939 \mu \mathrm{g} \mathrm{kg}^{-1}$ with higher concentrations found in CK-1, SS-7, BG-14 and BG-15.

The application of isomeric ratios for source diagnosis in these samples was quite difficult as some PAH compounds were below their LOQs. However, the Flt/(Flt+Pyr) can be applied, since these compounds were detected in $85 \%$ of the samples. The Flt/(Flt+Pyr) ratio of 0.4 seems to be petroleum/wood combustion transition point, though not definite. Ratios between 0.40 and 0.50 are more characteristics of liquid fossil fuel (vehicle or crude oil combustion), whereas ratio $>0.5$ are characteristics of grass, wood, or coal combustion (Essumang et al., 2012). The estimated Flt/(Flt+Pyr) ratio in this study ranged from 0.02 to 0.95, which indicates that the sources of PAHs in these samples were primarily from contamination of vegetable oil, vehicular emissions, and fuel type (wood/charcoal) used during the preparation of these foods. The low molecular weight PAHs of the three ringed compounds are the products of low temperature pyrogenic processes, such as wood combustion.

The calculation of dietary intake of PAHs in this study was based on the European Food Safety Authority (EFSA) indicators for occurrence and effects of PAHs in foods (PAH2, PAH4, and PAH8). The ingestion rate of $8.4 \mathrm{~g}$ per day based on the per capita consumption of bread and a reference body weight of $60 \mathrm{~kg}$ were used for the estimation of dietary intake of PAHs. The margin of exposure (MOE) approach was adopted for risk assessment; the MOE is the ratio of the benchmark dose lower limit $\left(\mathrm{BMDL}_{10}\right)$ to the estimated human intake of the compound. The $\mathrm{BMDL}_{10}$ is the lower bound of a $95 \%$ confidence interval on the Benchmark Dose (BMD) that produced a 10\% tumour incidence. MOE values less than 10000 indicate serious health effects, while MOE values greater than 10000 indicate no adverse effects to humans by the contaminants (EFSA, 2008). This point was chosen on the dose response curve as a reference point (LARSEN, 2006). The calculated BMDL10 values were $0.07,0.17,0.34$, and $0.49 \mathrm{mg} \mathrm{kg}^{-1}$ b.w. day ${ }^{-1}$ for BaP, PAH2, PAH4, and PAH8, respectively. The estimated daily intake of $\mathrm{BaP}$ and any of the EFSA suggested indicators for occurrence and effects of PAHs in foods, such as PAH2, PAH4, and PAH8 ranged from 1.9 
to $271.4 \mathrm{ng} \mathrm{kg}^{-1}$ b.w. day ${ }^{-1}$ in four of these samples where higher molecular weight PAHs were detected. The estimated margin of exposure from the consumption of these four samples (CK-1, SS-7, BG-14, and BG-15) based PAH8 were less than 10 000, which indicates health concern.

\section{Conclusions}

The results of the present study indicated that baked products were mainly contaminated with 2-, 3-, and 4-ring PAHs, which suggested that the contamination of these food items originated from automobile emissions, the combustion products of the fuel types used in the processing of these foods, baking procedure, and temperature. Benzo(a)pyrene concentrations in all samples were detected at concentrations below the prescribed limit for $\mathrm{BaP}$ in cereal based products except for one sample. Generally, the concentrations of total PAHs reported in this study were higher than levels reported in baked products in literature.

\section{References}

Ahmed, M.T., Abdel Hadi, E.S., El-Samahy, S. \& Youssof, K. (2000): The influence of baking fuel on the residues of polycyclic aromatic hydrocarbons and heavy metals in bread. J. Hazard. Mater., 80, 1-8.

Akpambang, V.O.E., Purcaro, G., Lajide, L., Amoo, I.A., Conte, L.S. \& Moret, S. (2009): Determination of polycyclic aromatic hydrocarbons (PAHs) in commonly consumed Nigeria smoked/grilled fish and meat. Food Addit. Contam., 26, 1096-1103.

Al-Rashdan, A., Helaleh, M.I.H., Nisar, A., Ibtisam, A. \& Al-Ballam, Z. (2010): Determination of the levels of polycyclic aromatic hydrocarbons in toasted bread using gas chromatography mass spectroscopy. Int. J. Anal. Chem., Article ID 821216, 8 pages doi:10.1155/2010/821216.

Ciecierska, M. \& Obiedzinski, M. (2007): Influence of smoking process on polycyclic aromatic hydrocarbons content in meat products. Acta Sci. Pol. Technol. Aliment., 6(4), 17-28.

Essumang, D.K., Dodoo, D.K. \& AdjeI, J.K. (2012): Polycyclic aromatic hydrocarbon (PAH) contamination in smoke-cured fish products. J. Food Compos. Anal., 27, 128-138.

EC (2006): European Commission, Commission Regulation No. 1881/2006 of the December 2006 setting maximum levels for certain contaminants in foodstuffs. Official Journal of the European Union.

EFSA (2008): Polycyclic aromatic hydrocarbons in food. Scientific opinion of the panel on contaminants in food chain (Adopted on 9 June, 2008) European Food Safety Authority, EFSA Journal, 724, 1-114.

LARsEn, J.C. (2006): Risk assessment of chemical in European traditional foods. Trends Food Sci. Tech., 17, 471481.

Nieva-Cano, M.J., Rubio-Barroso, S. \& Santos-Delgado, M.J. (2001): Determination of PAH in food samples by HPLC fluorimetric detection following sonication extraction without sample clean up. Analyst, 126, 13261331.

Orecchio, S. \& Papuzza, V. (2009): Levels, finger and daily intake of polycyclic aromatic hydrocarbons (PAHs) in bread baked using wood as fuel. J. Hazard. Mater., 164, 876-883.

Rey-Salgueiro, L., Garcia-Falcón, M.S., Martinez-Carballo, E. \& Simal-Gándara, J. (2008): Effects of toasting procedures on the levels of polycyclic aromatic hydrocarbons in toasted bread. Food Chem., 108, 607-615.

Ziegenhals, K., Spear, K. \& JiRA, W. (2009): Polycyclic aromatic hydrocarbons (PAH) in chocolates on the German market. J. Verbr. Lebensm., 4, 128-135. 